Int Arch Allergy Immunol 2021;182:324-338

DOI: $10.1159 / 000514204$
Received: December 3, 2020

Accepted: December 15, 2020

Published online: February 10, 2021

\title{
Potential Interplay between Nrf2, TRPA1, and TRPV1 in Nutrients for the Control of COVID-19
}

\author{
Jean Bousquet ${ }^{\mathrm{a}, \mathrm{b}}$ Wienczyslawa Czarlewski ${ }^{\mathrm{c}, \mathrm{d}}$ Torsten Zuberbier ${ }^{\mathrm{a}}$ Joaquim Mullol ${ }^{\mathrm{e}}$ \\ Hubert Blain $^{f}$ Jean-Paul Cristol ${ }^{g}$ Rafael De La Torre ${ }^{h, i, j}$ Nieves Pizarro Lozano ${ }^{i}$ \\ Vincent Le Moing $^{k} \quad$ Anna Bedbrook $^{b, d}$ loana Agachel Cezmi A. Akdis $^{m} \quad$ G. Walter Canonican \\ Alvaro A. Cruz ${ }^{\circ}$ Alessandro Fiocchi ${ }^{p}$ Joao A. Fonsecaq, ${ }^{q}$ Susana Fonsecas ${ }^{s}$ Bilun Gemicioğlu ${ }^{t}$ \\ Tari Haahtela ${ }^{\mathrm{u}}$ Guido laccarinov $^{\mathrm{v}}$ Juan Carlos Ivancevich ${ }^{\mathrm{w}}$ Marek Jutel ${ }^{\mathrm{x}}$ Ludger Klimek $^{\mathrm{y}}$ \\ Helga Kraxner $^{z}$ Piotr Kuna ${ }^{A}$ Désirée E. Larenas-Linnemann ${ }^{B}$ Adrian Martineau ${ }^{C}$ Erik Melén ${ }^{D}$ \\ Yoshitaka Okamoto $^{\mathrm{E}}$ Nikolaos G. Papadopoulos ${ }^{\mathrm{F}, \mathrm{G}}$ Oliver Pfaar ${ }^{\mathrm{H}} \quad$ Frederico S. Regateiro $^{\mathrm{l}, J}$ \\ Jacques Reynes $^{\mathrm{k}}$ Yves Rolland ${ }^{\mathrm{K}}$ Philip W. Rouadi ${ }^{\mathrm{L}}$ Boleslaw Samolinski $^{\mathrm{M}}$ Aziz Sheikh $^{\mathrm{N}}$ \\ Sanna Toppila-Salmi ${ }^{u}$ Arunas Valiulis ${ }^{\circ}$ Hak-Jong Choi ${ }^{P}$ Hyun Ju Kim ${ }^{Q}$ Josep M. Anto ${ }^{i, j, R, S}$
}

aDepartment of Dermatology and Allergy, Comprehensive Allergy Center, Charité, and Berlin Institute of Health, Comprehensive Allergy Center, Universitätsmedizin Berlin, Humboldt-Universität zu Berlin, Berlin, Germany; bUniversity Hospital and MACVIA France, Montpellier, France; ' ${ }^{\circ}$ Medical Consulting Czarlewski, Levallois, France;

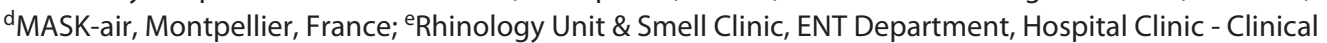
\& Experimental Respiratory Immunoallergy, IDIBAPS, CIBERES, Universitat de Barcelona, Barcelona, Spain; fDepartment of Geriatrics, Montpellier University Hospital, Montpellier, France; 9Laboratoire de Biochimie et Hormonologie, PhyMedExp, Université de Montpellier, INSERM, CNRS, CHU de, Montpellier, France; ${ }^{\text {hCIBER }}$ Fisiopatologia de la Obesidad y Nutrición (CIBEROBN), Madrid, Spain; iIMIM (Hospital del Mar Research Institute), Barcelona, Spain; 'Departament de Ciències Experimentals i de la Salut Toxicologia, Universitat Pompeu Fabra (UPF), Barcelona, Spain; kMaladies Infectieuses et Tropicales, CHU, Montpellier, France; 'Faculty of Medicine, Transylvania University, Brasov, Romania; ${ }^{\mathrm{m} C h r i s t i n e ~ K u ̈ h n e ~-~ C e n t e r ~ f o r ~ A l l e r g y ~ R e s e a r c h ~ a n d ~ E d u c a t i o n ~(C K-C A R E), ~}$ Swiss Institute of Allergy and Asthma Research (SIAF), University of Zurich, Zurich, Switzerland; nersonalized Medicine, Asthma and Allergy, Humanitas Clinical and Research Center IRCCS and Department of Biomedical Sciences, Humanitas University, Pieve Emanuele, Italy; ${ }^{\circ}$ Fundação ProAR, Federal University of Bahia and GARD/ WHO Planning Group, Salvador, Brazil; ${ }^{P}$ Division of Allergy, The Bambino Gesù Children's Research Hospital IRCCS, Rome, Italy; ${ }^{9}$ CINTESIS, Center for Research in Health Technologies and Information Systems, Faculdade de Medicina da Universidade do Porto, Porto, Portugal; 'MEDIDA, Lda, Porto, Portugal; ' GreenUPorto - Sustainable Agrifood Production Research Centre, DGAOT, Faculty of Sciences, University of Porto, Vila do Conde, Portugal; tDepartment of Pulmonary Diseases, Istanbul University-Cerrahpasa, Cerrahpasa Faculty of Medicine, Istanbul, Turkey; "Skin and Allergy Hospital, Helsinki University Hospital, and University of Helsinki, Helsinki, Finland; 'Interdepartmental Center of Research on Hypertension and Related Conditions CIRIAPA, Federico II University,

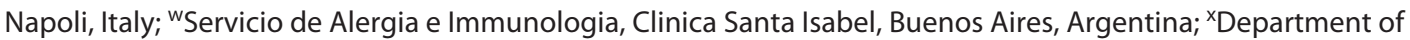
Clinical Immunology, Wrocław Medical University and ALL-MED Medical Research Institute, Wrocław, Poland; yCenter for Rhinology and Allergology, Wiesbaden, Germany; ${ }^{2}$ Department of Otorhinolaryngology, Head and Neck Surgery, Semmelweis University, Budapest, Hungary; ${ }^{A}$ Division of Internal Medicine, Asthma and Allergy, Barlicki University Hospital, Medical University of Lodz, Lodz, Poland; ${ }^{B}$ Center of Excellence in Asthma and Allergy, Médica Sur Clinical Foundation and Hospital, Mexico City, Mexico; ' Institute for Population Health Sciences, Barts and The London School of Medicine and Dentistry, Queen Mary University of London, London, UK; DInstitute of

Jean Bousquet

Department of Allergology, Macvia France 273 Avenue d'Occitanie FR-34090 Montpellier (France) jean.bousquet@orange.fr 
Environmental Medicine, Karolinska Institutet and Sachs' Children's Hospital, Stockholm, Sweden; EDepartment of Otorhinolaryngology, Chiba University Hospital, Chiba, Japan; FDivision of Infection, Immunity \& Respiratory Medicine, Royal Manchester Children's Hospital, University of Manchester, Manchester, UK; GAllergy Department, 2nd Pediatric Clinic, Athens General Children's Hospital "P\&A Kyriakou," University of Athens, Athens, Greece; ${ }^{H}$ Section of Rhinology and Allergy, Department of Otorhinolaryngology, Head and Neck Surgery, University Hospital Marburg, Philipps-Universität Marburg, Marburg, Germany; 'Allergy and Clinical Immunology Unit, Centro Hospitalar e Universitário de Coimbra, Faculty of Medicine, Institute of Immunology, University of Coimbra, Coimbra, Portugal; ' Faculty of Medicine, ICBR - Institute for Clinical and Biomedical Research, CIBB, University of Coimbra, Coimbra, Portugal; ${ }^{K} \mathrm{CHU}$ Toulouse, Toulouse, France; 'Department of Otolaryngology-Head and Neck Surgery, Eye and Ear University Hospital, Beirut, Lebanon; ${ }^{M}$ Department of Prevention of Environmental Hazards and Allergology, Medical University of Warsaw, Warsaw, Poland; NUsher Institute, The University of Edinburgh, Edinburgh, UK; ${ }^{O}$ Vilnius University Faculty of Medicine, Institute of Clinical Medicine \& Institute of Health Sciences,

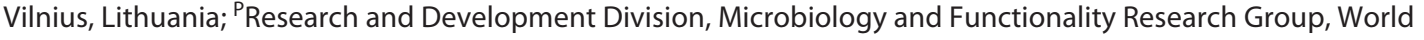

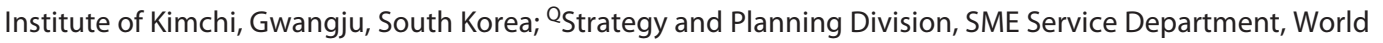
Institute of Kimchi, Gwangju, South Korea; ${ }^{R}$ CIBER Epidemiología y Salud Pública (CIBERESP), Barcelona, Spain; SISGlobAL, Barcelona, Centre for Research in Environmental Epidemiology, Barcelona, Spain

\section{Keywords}

COVID-19 · Nrf2 · TRAP-1 · Broccoli · Pungent foods · Cough challenge

\begin{abstract}
In this article, we propose that differences in COVID-19 morbidity may be associated with transient receptor potential ankyrin 1 (TRPA1) and/or transient receptor potential vanilloid 1 (TRPV1) activation as well as desensitization. TRPA1 and TRPV1 induce inflammation and play a key role in the physiology of almost all organs. They may augment sensory or vagal nerve discharges to evoke pain and several symptoms of COVID-19, including cough, nasal obstruction, vomiting, diarrhea, and, at least partly, sudden and severe loss of smell and taste. TRPA 1 can be activated by reactive oxygen species and may therefore be up-regulated in COVID-19. TRPA1 and TRPV1 channels can be activated by pungent compounds including many nuclear factor (erythroid-derived 2) (Nrf2)-interacting foods leading to channel desensitization. Interactions between Nrf2-associated nutrients and TRPA1/TRPV1 may be partly responsible for the severity of some of the COVID-19 symptoms. The regulation by Nrf2 of TRPA1/TRPV1 is still unclear, but suggested from very limited clinical evidence. In COVID-19, it is proposed that rapid desensitization of TRAP1/TRPV1 by some ingredients in foods could reduce symptom severity and provide new therapeutic strategies.

(c) 2021 S. Karger AG, Basel
\end{abstract}

Transient Receptor Potential Channels in COVID-19

\section{Introduction}

The transient receptor potential (TRP) vanilloid 1 (TRPV1) and ankyrin 1 (TRPA1) are members of the TRP superfamily of structurally related, nonselective cation channels. TRPV 1 and TRPA1 are frequently co-localized in sensory neurons, and interact to modulate function. They co-localize with neuropeptides such as substance P, CGRP and the receptor for nerve growth factor, and have a low threshold for various inflammatory mediators such as bradykinins, histamines, and eicosanoids. They are also expressed in many non-neuronal cells such as vascular smooth muscle, monocytes, lymphocytes, keratinocytes, epithelial cells, and endothelium [1].

TRPA1, an excitatory ion channel originally associated with the receptor of mustard oil in sensory neurons [2], plays a pivotal role in detecting cysteine-reactive irritants and in augmenting sensory or vagal nerve discharges to evoke pain and cough. TRPA1 induces inflammation, plays a key role in the physiology of almost all organs [3], and exhibits the highest sensitivity of TRPs to oxidants. TRPA 1 can be activated by cold, heat, pungent compounds, mechanical stimuli, endogenous signals of inflammation, and oxidative stress [4]. Its function is modulated by multiple factors, including $\mathrm{Ca}^{2+}$, trace metals, $\mathrm{pH}$, reactive oxygen species (ROS), nitrogen, and carbonyl species.

TRPV1, also known as the capsaicin receptor, has a major function in the detection and regulation of body temperature [5]. TRPV1 provides a sensation of heat and pain (nociception). In primary afferent sensory neurons,

Int Arch Allergy Immunol 2021;182:324-338 
it cooperates with TRPA1 to mediate the detection of noxious environmental stimuli [6]. It can also be activated by some endogenous lipid-derived molecules, PGE2, acidic solutions, pungent chemicals, food ingredients such as capsaicin, and toxins [7]. TRPV1 is a sensor of oxidative stress, but to a lesser extent than TRPA1.

COVID-19 morbidity cannot be appreciated across countries because there is no common method of assessment. However, death rates may be a proxy for COVID-19 severity. There have been large country variations in COVID-19 death rates $[8,9]$. Some of the very low death rate settings, such as those of Eastern Asia, Central Europe, the Balkans and Africa, have a common feature of eating large quantities of fermented vegetables [10] and, in some countries, spices. There appears to be an inverse correlation between spice consumption and COVID-19 mortality [11], and the same countries are often those with a high consumption of fermented vegetables and spices $[12,13]$.

A common denominator in all clinical manifestations associated with COVID-19 appears to be the oxidative stress storm [14]. The intake of fermented vegetables is associated with activation of the nuclear factor (erythroidderived 2) (Nrf2)-like antioxidant transcription factor $[10,15,16]$. There are many Nrf2-interacting nutrients [17] (berberine, curcumin, epigallocatechin gallate, genistein, quercetin, resveratrol, and sulforaphane) that act similarly to reduce insulin resistance, endothelial damage, lung injury, and cytokine storm (Bousquet et al. [10], submitted). It has been proposed that Nrf2-interacting foods and nutrients can re-balance insulin resistance and have a significant effect on COVID-19 severity [10, 18-20]. However, other mechanisms may also be involved as pungent foods and spices interact through TRPA1 and TRPV 1 [21]. Activation of TRP channels (TRPV1, TRPV4, TRPM3, TRPM8, and TRPA1) enables cross talk between neurons, immune cells, and epithelial cells to regulate a wide range of inflammatory actions [22].

In this article, we examined whether (i) TRPA1 and/or TRPV1 may be associated with COVID-19 symptoms and morbidity; (ii) TRPA1 and/or TRPV1 may be involved in COVID-19 risk factors (obesity and diabetes), lung injury, and endothelial damage; (iii) TRPV1 may be associated with TRAP1 in COVID-19; (iv) Nrf2, the most potent antioxidant system of the human body, may regulate TRPA1 and/or TRPV1; (v) Nrf2-interacting nutrients act on TRPA1 and/or TRPV1; and (vi) the results of 3 clinical cases treated with broccoli seed capsules (broccoli) containing glucoraphanin might be explained by TRPA1 and/or TRPV1.

\section{TRPA1/TRPV1 and COVID-19}

\section{COVID-19 Symptoms}

Several COVID-19 Symptoms Are Associated with

TRPA1 and/or TRPV1

Cough is a major COVID-19 symptom [23], but is not necessarily associated with severity. The cough reflex is induced by the activation of airway sensory nerves and TRP ion channels related to the vanilloid (TRPV) family and TRPA1 [24-26]. TRPA1 is abundantly expressed on the innervations of the entire respiratory tract. These include the $\mathrm{C}$-fibers of the trigeminal and vagal ganglia as well as nasal, tracheal, bronchial, and alveolar epithelial cells, bronchial smooth muscle cells and $\mathrm{CD}^{4+} \mathrm{T}$ cells [27]. C-fibers largely "sense" the presence of potentially toxic inhaled irritants and toxicants. TRPA1 represents a gateway to airway irritation and reflex responses induced by inhaled oxidants [28], air pollutants, and tobacco smoking [29]. Capsaicin has been largely used in cough provocation tests related to airway mucosal TRPV1 receptors in sensory nerves, reacting to noxious stimuli [24]. Both TRPA1 and TRPV1 mediate cigarette smoke-induced damage of the bronchial and alveolar epithelial cells via modulation of oxidative stress, inflammation, and mitochondrial damage [30]. This suggests a complex regulatory role of TRAP1 and TRPV1 in acute and chronic airway inflammation [31].

Smell and taste disorders are very common in COVID-19 [32-37]. TRPA1 and TRPV1 are among the TRP channels involved in nociception and are excited by pungent odorous substances [38]. Associations have been observed between TRPA1 genetic variants and increased sensitivity to thermal pain stimuli or increased olfactory sensitivity [39]. Capsaicin is also partly involved in smell and taste perception with sensory (olfactory) and sensitive (trigeminal) perceptions coming together [40]. In addition, most odorants have sensitive (trigeminal) characteristics, this being linked with nasal hyper-reactivity to strong odorants (sometimes identified as "hyperosmia" by patients with sino-nasal inflammation). The intranasal trigeminal system is a third chemical sense in addition to olfaction and gustation. In the nasal cavity, high levels of trigeminal receptor expression were found for TRPV1 and TRPA 1 [38]. The sensitivity of the intranasal trigeminal system to chemicals was found to be partly mediated by TRPA1 [41]. The mammalian taste system consists of taste buds found throughout the oral cavity. TRP channels are important in gustatory processing [42]. They are very sensitive to changes in temperature and are activated by many compounds found in plants, often used as spices 
[43]. TRPA1 is mostly an acid-sensing and epithelial sodium channel [44], whereas TRVP1 is also sensitive to temperature and bitter taste [45].

Loss of appetite is common [46] and may be severe in COVID-19. It has been suggested that TRPA1 may play a role in food intake and satiety [47-50]. In animals, TRPA 1 activation increases appetite [51]. TRPV1 can have an impact on appetite through control of appetite hormone levels or modulation of gastrointestinal vagal afferent signalling [52].

Nasal obstruction alone is relatively common in COVID-19. In 2 studies, nasal obstruction was frequently reported, but not correlated with olfactory dysfunction [53, 54]. In rhinitis, nasal itch is related to TRPV1 [55]. Patients suffering from rhinitis exhibit a decreased threshold to the TRPA1 agonist allyl isothiocyanate (AITC). This correlates with symptoms and, in animals, is resolved after chemical destruction of the nasal sensory nerves [56-58]. Capsaicin was found to be an option for the treatment of nonallergic rhinitis [59].

Nausea, vomiting, and/or diarrhea are relatively common symptoms of COVID-19 [46]. TRPA1 is expressed in both dorsal root ganglions and nodose ganglion neurons innervating the stomach, as well as in nerve fibers of the gastric wall. Gastric administration of garlic powder containing the TRPA1-agonist allicin induces specific epigastric symptoms and gastric relaxation in healthy subjects [60]. Capsaicin can induce gastroesophageal and abdominal pain, heartburn, bloating, and/or dyspepsia through TRPV1 [61-63].

COVID-19 is often associated with myalgia, back pain, widespread hyperalgesia, and headache [34, 64]. TRPA1 and TRPV1 are involved in acute and chronic pain and in migraine $[3,65,66]$. They may also be partly involved in some of the COVID-19 symptoms. Some of the other COVID-19 symptoms, such as fever or fatigue, appear less likely to be associated with TRPA1 and/or TRPV1.

\section{COVID-19 Risk Factors, TRPA1, and TRPV1}

Obesity and, to a lesser extent, diabetes are risk factors for COVID-19 severity. The importance of TRPA1 on the metabolic syndrome, obesity, and diabetes is usually indirect using agonists that have multiple actions including TPRA1 and TPRV1. It is therefore difficult to differentiate the 2 TPR channels. Animal models are of importance for a more precise assessment of the mechanisms [67, 68].

TRPV1 and TRPA1 have been associated with control of weight, pancreatic function, hormone secretion, thermogenesis, and neuronal function. This suggests a potential therapeutic value of these channels in obesity and di- abetes [69, 70]. Cinnamaldehyde (in cinnamon) may have an adjunct future potential role in the treatment of diabetes and its complications [12]. A garlic supplement plays a positive and sustained role in blood glucose, total cholesterol, and in high/low density lipoprotein regulation in the management of diabetes [71]. However, these effects can be mediated by multiple pathways. As an example, cinnamaldehyde exerts its effects through its action on multiple signalling pathways [70], including TRPA1-ghrelin [72] and Nrf2.

\section{Lung Injury}

Acute respiratory distress syndrome is one of the major causes of mortality associated with COVID-19. TRP ion channels are involved in lung injury. It has been proposed that morbidity, severity of the disease, and underlying physiological events leading to mortality are closely linked with the TRPV1-expressing neuronal system (afferent/efferent neurons) in the lungs [73]. TRVP1 and TRPV4 are involved in pulmonary chemical injuries [74]. In mouse acute lung injury models, the bacterial endotoxin LPS involves both TRPV1 and TRPA1 $[31,73,75]$. Ventilator-induced lung injury contributes to mortality in patients with acute lung injury by increasing inflammation. In a rat model of ventilator-induced lung injury, a TRPA1 inhibitor significantly reduced both inflammation in the lung tissues and the generation of ROS [76]. Unsaturated aldehydes generated during incomplete combustion - such as acrolein - are highly toxic for the lungs. TRPA1 protects against high-level acrolein-induced toxicity in mice [77]. The simultaneous activations of TRPA1 and TRPV1 by their respective selective agonists are far more effective than single agonists taken separately [78]. In a mouse model, liquiritin, a novel inhibitor of TRPV1 and TRPA1, protects against LPS-induced acute lung injury [75]. TRPA1 may be involved in the development and progression of heart failure, myocardial ischemia-reperfusion injury, myocardial fibrosis, and arrhythmia that may aggravate lung injury [79].

\section{TRPA1/TRPV1 and Nrf2}

\section{TPRA1/TRPV1 Are Sensory Receptors for Multiple Products of Oxidative Stress}

Oxidative stress, characterized by an imbalance between oxidants and antioxidants in favour of oxidants, leads to the disruption of redox signalling and physiological function. Redox signalling-induced changes are performed by ROS and reactive nitrogen species (RNS) [80]. 
ROS is a collective term that includes superoxide $\left(\mathrm{O}_{2}{ }^{-}{ }^{-}\right)$, hydrogen peroxide $\left(\mathrm{H}_{2} \mathrm{O}_{2}\right)$, hydroxyl radical $\left(\mathrm{OH}^{*}\right)$, singlet oxygen $\left({ }^{1} \mathrm{O}_{2}\right)$, peroxyl radical (LOO'), alkoxyl radical (LO'), lipid hydroperoxide ( $\mathrm{LOOH})$, hypochlorous acid $(\mathrm{HOCl})$, and ozone $\left(\mathrm{O}_{3}\right)$, among others [81].

TRPA1 also functions as a sensor, activated by ROS and modulated by the occurrence of intracellular changes in oxygen levels. Multiple agents produced during oxidative stress can activate TRPA1 expressed in sensory neurons [82]. Besides ROS, TRPA1 channels are also activated by RNS, including nitric oxide (NO) [83]. Although many studies have been performed, the relevance of TRPA1 activation for cell signalling in oxidative stress is still unclear [84]. In the upper and lower airways, TRPA1, found in vagal sensory endings responsive to hypoxic conditions, may serve as a rapid alarm system during abnormal oxidative conditions [84].

The potential links between TRPA1 and TRPV1 with ROS production has been proposed in chronic diseases. In endothelial cells, TRPV1 stimulation activates endothelial NO synthase (eNOS) [85] and NO production, leading to smooth muscle relaxation and vasodilation, and concomitant protection of endothelial cells from leukocyte adhesion. On vascular smooth muscle cells, capsaicin reduces the accumulation of lipids and cholesterol uptake in a $\mathrm{Ca}^{2+}$-, calcineurin- and protein kinase A-dependent manner, via increased expression of ATP-binding cassette transporter A1 and reduced expression of LDL-related protein 1 [86]. In in vivo models, dietary capsaicin treatment improves atherosclerosis by reducing the inflammatory events that cause atherosclerotic plaque formation. Since oral capsaicin treatment cannot cause the increase in blood levels of capsaicin needed to act directly on cardiac or intravascular TRPV1 receptors, a remote activation should be suggested, which likely involves TRPV1 receptors localized on the capsaicin-sensitive sensory nerve terminals [87]. Indeed, experimental evidence proposes the protective roles of cardiac capsaicin-sensitive afferents and sensory TRPV1 receptors in myocardial protection through the release of sensory neuropeptides [88]. The chronic administration of systemic capsaicin induces sensory desensitization [89], leading to a model of Heart Failure with preserved Ejection Fraction (HFpEF). Mechanistically, this phenotype is due to reduced basal cardiac NO, superoxide, and peroxynitrite $\left(\mathrm{ONOO}^{-}\right)$formation, with impairment of the filling properties of the heart. The protective roles of the capsaicin-sensitive nerves and TRPV1 receptors on cardiac function are suggested.

Oxidative stress in the airways occurring through inflammatory mechanisms or following the inhalation of noxious agents causes cellular dysfunction. Oxidative stress activates vagal sensory C-fibers, initiating nerve action potentials that lead centrally to unpleasant sensations (e.g., cough, dyspnea, and chest-tightness) and to the stimulation/modulation of reflexes (e.g., cough, bronchoconstriction, respiratory rate, inspiratory drive). There is a key role for TRPA1, although TRPV1 may also play a role $[83,90]$.

\section{Nuclear factor (erythroid-derived 2)}

$\mathrm{Nrf2}$ is the major regulator of cellular resistance to oxidants. Nrf2 is mainly regulated by the Kelch-like ECHassociated protein 1 . Nrf2 activation, through constitutive mechanisms, is carried out by electrophilic compounds and oxidative stress, where some cysteine residues in Kelch-like ECH-associated protein 1 are oxidized. This results in a decrease in Nrf2 ubiquitination and an increase in its nuclear translocation and activation. In the nucleus, Nrf2 induces a variety of genes involved in the antioxidant defence [91].

\section{Interactions between Nrf2 and TRPA1}

It is possible that Nrf2 may play a major role in the modulation of TRPA1 by ROS. However, there are few studies assessing the interactions between $\mathrm{Nrf} 2$ and TRPA1, and their results are sometimes conflicting. Specific signalling pathways of lung ischemia-reperfusion injury impair Nrf2-antioxidant response and activate oxidative stress in the brainstem, thereby leading to the amplification of TRPA1, mostlikely via ROS [92]. Polysulfides (H2Sn) occur in the brain, activate TRPA1, and facilitate the translocation of Nrf2 [93]. TRPA1 knockdown exacerbates the infiltration of activated macrophages, renal inflammation, and renal injury in mice after ischemic reperfusion injury [94]. In different animal models, neuroprotection has been observed and associated with the activation of the Nrf2 pathway via antioxidative signalling pathways [95-98]. A neuronal redox-sensing $\mathrm{Ca}^{2+}$-influx channel, overexpressed in human cancer, upregulates $\mathrm{Ca}^{2+}$-dependent anti-apoptotic pathways to promote ROS resistance. Nrf2 directly controls TRPA1 expression, thus providing an orthogonal mechanism for protection against oxidative stress, together with canonical ROSneutralizing mechanisms [99].

\section{Interactions between Nrf2 and TRPV1}

There are few studies assessing the interactions between Nrf2 and TRPV1, and their results are sometimes conflicting. Capsaicin induces the production of ROS, which can induce Nrf2 activation and the induction of 
heme oxidase-1 expression [100]. TRPV1 activation induces calcium influx associated with an increasing expression of Nrf2-responsive antioxidant enzymes [101]. Ultraviolet irradiation causes cellular oxidative stress, stimulates 12-lipoxygenase and the product 12-hydroxyeicosatetraenoic acid, and then activates TRPV1. $\mathrm{A} \mathrm{Ca}^{2+}$ influx via TRPV1 is responsible for UVB irradiation-induced Nrf2 degradation [102].

\section{Activation and Desensitization of TRPA1 and TRPV1}

\section{Neurotropism of SARS-CoV-2}

Coronaviruses are neurotropic. The expression of ACE2 in human neurons supports the neuro-invasive potential of SARS-CoV-2 [103-105]. In a human induced pluripotent stem cell-derived BrainSphere model, ACE2 was detected and SARS-CoV-2 was found to replicate [106]. In an animal study assessing olfactory damage, ACE2 and the protease TMPRSS2 were expressed in the sustentacular cells of the olfactory epithelium, but much less in most of the olfactory receptor neurons [107]. These results propose a dual model: direct viral invasion or a bystander injury after the infection of epithelial/endothelial cells [108].

\section{Many Nrf2-Interacting Nutrients Are TRPA1 and \\ TRPV1 Agonists}

TRP channels are polymodal channels and most of the superfamily members can be activated by a multitude of stimuli [109]. Several Nrf2-interacting nutrients are direct TRPA1 activators [21, 110]. These include: (i) allyl isothiocyanates (AITC: pungent components of mustard, horseradish, and wasabi [2]), (ii) cinnamaldehyde from cinnamon [70], (iii) allicin, an organosulfur compound from garlic [111], (iv) green tea polyphenols [112, 113], and (v) 3 glucosinolates from Sisymbrium officinale (isopropylisothiocyanate and 2-buthylisothiocyanate) or Moringa oleifera (4-[( $\alpha$-l-rhamnosyloxy) benzyl] isothiocyanate) $[114,115]$. Sulforaphane, an AITC and the most potent natural Nrf2 activator, does not appear to interact with TRPA1. The plant polyphenol resveratrol [116] may have an agonist or antagonist effect [117]. An indirect agonist effect [118] was found via the N-methyl-D-aspartate receptor in vivo [119]. TRPA1 may serve as a downstream target of pro-nociceptive ion channels such as $\mathrm{N}$ methyl-D-aspartate receptors [120] (Table 1).

Many TRPV1 agonists also interact with Nrf2 and/or TRPA1. TRPV1 is a sensor stimulated by several spices including capsaicin (red pepper), piperine (black pepper), gingerol, and zingerone (ginger), pungent com-

Transient Receptor Potential Channels in COVID-19 pounds from onion and garlic, eugenol (clove), and camphor. TRPV1 is also activated by AITC, present in mustard, horseradish, and wasabi [121], and by resiniferatoxin, a toxin of tropical Euphorbia plants [122].

There is a substantial overlap of electrophilic ligands between TRPA1 and Nrf2 [21]. However, not all Nrf2interacting nutrients are activators of TRPA1. For example, mustard oil does not interact with Nrf2, whereas sulforaphane does not interact with TRPA1 or TRPV1.

\section{Desensitization of TRP}

The pungent effects of chili and other spices are rapidly reduced by high or repeated doses [21]. This was first described for capsaicin, an active component of chili peppers [165]. Desensitization of TRPV1 underlies the paradoxical analgesic effect of capsaicin. The TRPV1 receptors begin a refractory state, commonly termed as desensitization, that leads to the inhibition of receptor function [21]. The acute desensitization of TRVP1 accounts for most of the reduction in responsiveness occurring within the first few $(\sim 20)$ seconds after the vanilloids are administered to the cell for the first time. Several signalling pathways including calcineurin, calmodulin, or the decrease of phosphatidylinositol 4,5-bisphosphate [166] are involved in TRPV1 desensitization. Oxidative stress decreases phosphatidylinositol 4,5-bisphosphate [167], and receptor desensitization may possibly be obtained at lower doses of agonists in COVID-19. Another form of desensitization is "tachyphylaxis," which is a reduction in the response to repeated applications of vanilloid [168].

TRPA1 is desensitized by homologous (mustard oil; a TRPA1 agonist) or heterologous (capsaicin; a TRPV1 agonist) agonists via $\mathrm{Ca}^{2+}$-independent and $\mathrm{Ca}^{2+}$-dependent pathways in the sensory neurons [169]. There is a heterologous desensitization of TRPA1 via a TRPV1 pathway $[170,171]$. Resveratrol or AITC act as activators and desensitizers of TRPA1 channels [153]. High concentrations of para-benzoquinone caused rapid activation of TRAP1 followed by fast decline in a cysteine-dependent desensitization mechanism [172]. The contractile effect of TRAP1 in isolated mouse intestine can be induced by AITC. Repeated doses induce desensitization [173]. The electrophilic fatty acid $\mathrm{NO}_{2}-\mathrm{OA}$ acts on TRP channels to initially depolarize and induce firing in sensory neurons followed by desensitization and suppression of firing [174]. $\mathrm{NO}_{2}$-OA attenuates intracellular oxidative stress through Nrf2 and suppression of NADPH oxidase [175].

Although data are sometimes conflicting, interactions between TRPA1 and TRPV1 can modulate receptor de- 
Table 1. Examples of Nrf2-, TRPA1-, and TRPV1-interacting nutrients

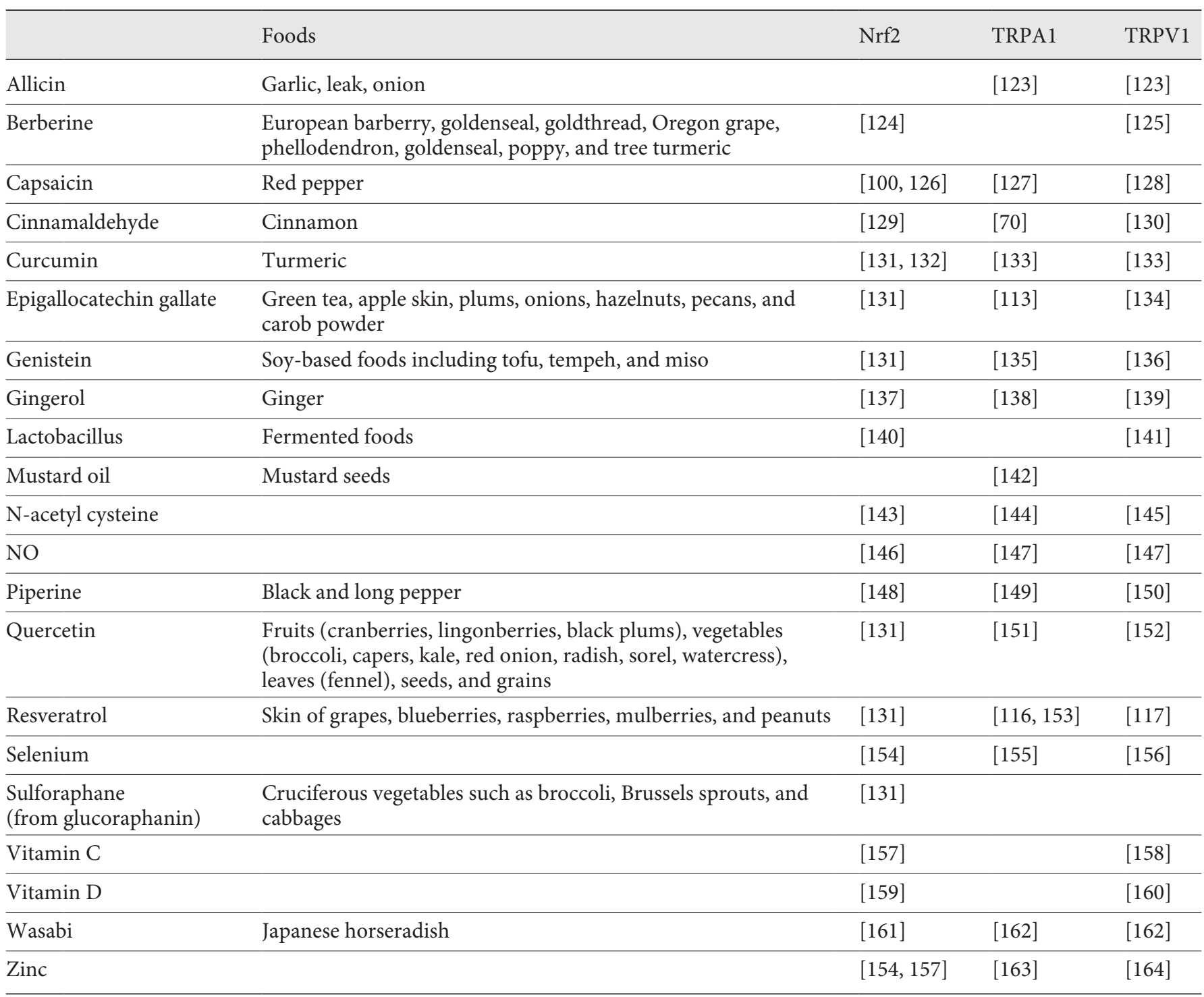

TRPA1, transient receptor potential ankyrin 1; TRPV1, transient receptor potential vanilloid 1; Nrf2, nuclear factor (erythroidderived 2); NO, nitric oxide.

sensitization. Using patch-clamp electrophysiology, the co-expression and interaction of TRPA1 with TRPV1 proved to be the most critical for the differential sensitization of sensory neurons for pain [176]. On the other hand, the selective TRPA1 agonist (AITC) resulted in the restoration of sensitivity to capsaicin TRPV1 channels (resensitization TRPV1 channels) [177]. The attenuation of experimental colitis by capsazepine (capsaicin-induced denervation $\mathrm{CPZ}$ ) is attributed to its antagonistic action on TRPV1. It exerts its anti-inflammatory effects via profound desensitization of TRPA1 [178].
Nicotine activates TRAP1 [179] and TRPV1 [180]. The prevalence of smoking among hospitalized COVID-19 patients is low [181]. Although many different mechanisms are proposed, the desensitization of TRPA1/ TRPV 1 by nicotine may be one possibility. If this were the case, it would show that TRPA1/TRPV1 may be involved in severe COVID-19.

Sensory receptors like TRPA1 or TRPV1 may serve as gate-keepers in optimizing spice intake, thereby avoiding over-exposure and exemplifying the sensory and metabolic interactions of spicy nutraceuticals. In this scenario, 


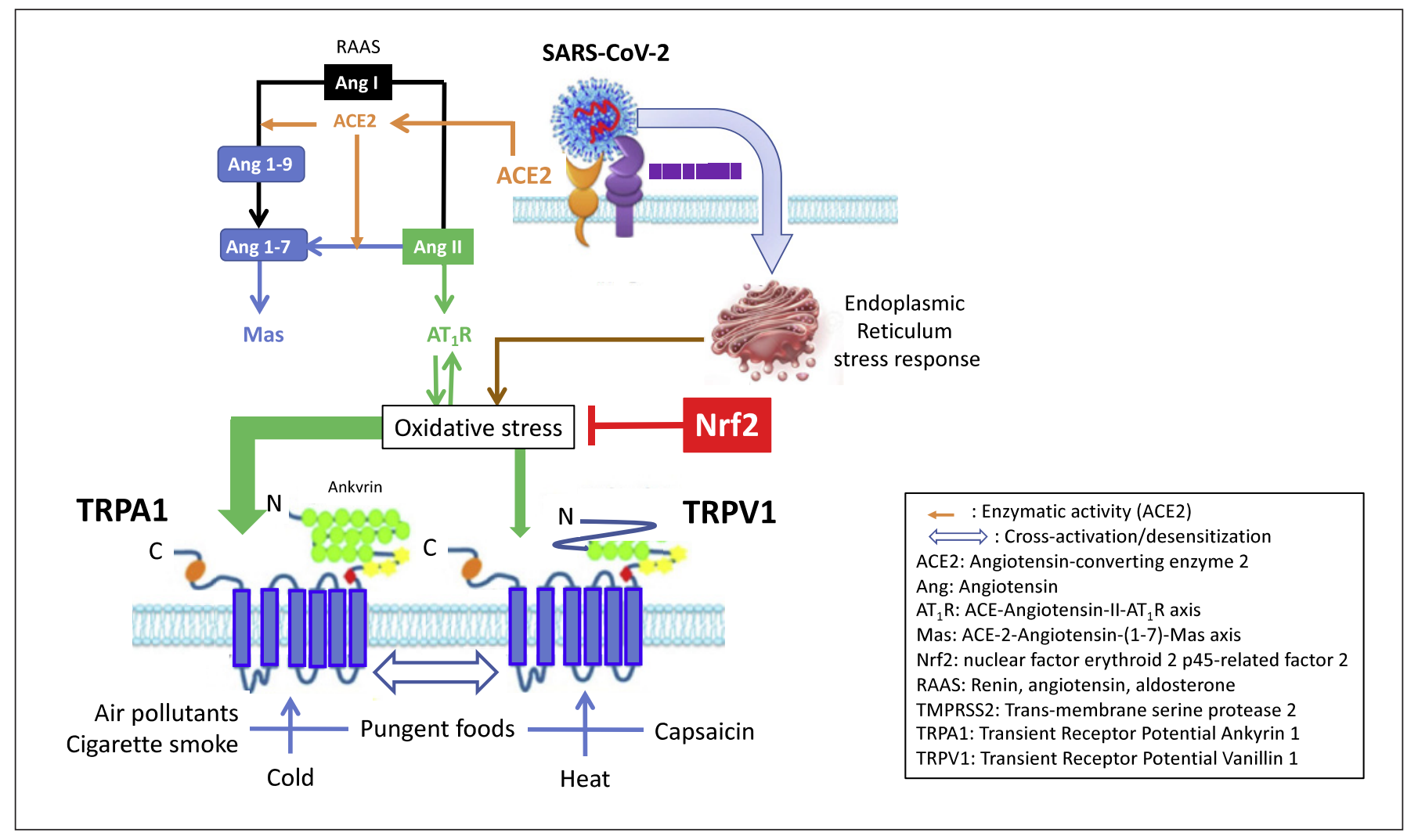

Fig. 1. Interactions between TRPs and oxidative stress in COVID-19 (modified from $[10,110]$ ). SARS-CoV-2 binds to the cell through ACE2 that is downregulated. Angiotensin I is transformed in angiotensin II AT1R pathways, inducing oxidative stress. When SARS-CoV-2 enters the cell, it induces an endoplasmic reticulum stress response, inducing an oxidative stress among other pathways. The oxidative stress is inhibited by many antioxidants, but

desensitization might be an attempt to maintain an optimal intake of pungent compounds in spite of priming the metabolizing enzymes and a substantial higher and/or faster inactivation by metabolic clearance [21]. We propose that electrophilic ligands may activate and desensitize TRPA1 or TRPV1.

\section{TRPA1-TRPV1 and Acetaminophen}

Paracetamol (acetaminophen) has TRPA1-independent antipyretic effects [182] and TRPA1-dependent effects on pain [183]. The electrophilic metabolites $\mathrm{N}$-acetyl-p-benzoquinone imine (NAPQI, hepatotoxic metabolite) and p-benzoquinone, but not paracetamol itself, activate TRPA1 [82]. They also activate and sensitize TRPV1 by interacting with intracellular cysteines [184, 185]. NAPQI also directly activates Nrf2 [186], and benzoquinone desensitizes TRPA1 [172].

Transient Receptor Potential Channels in COVID-19
Nrf2 is the most potent one. The oxidative stress senses TRPA1 and, to a lesser extent, TRPV1. The activated TRPs are prone to be hyper-activated by various natural stimuli. Foods can activate Nrf2 and desensitize TRPs. TRPA1, transient receptor potential ankyrin 1; TRPV1, transient receptor potential vanilloid 1; Nrf2, nuclear factor (erythroid-derived 2).

The physiological and toxicological responses of paracetamol form a continuum coordinated by the Wnt and Nrf2 pathways. Therapeutic doses produce reactive ROS and NAPQI in the cytoplasm but result in little permanent damage [187]. At high doses, paracetamol can induce oxidative stress-mediated hepatotoxicity which is reduced by enhancing the Nrf2 pathway [188-190].

\section{Conclusions: Hypothetic Interactions of Nrf2, TRPA1/TRPV1, and COVID-19}

A common denominator in symptoms associated with COVID-19 appears to be the impaired redox homeostasis responsible for ROS accumulation [191]. Several mechanisms have been proposed involving, among others, the renin-angiotensin-aldosterone system [10] and/or endo- 


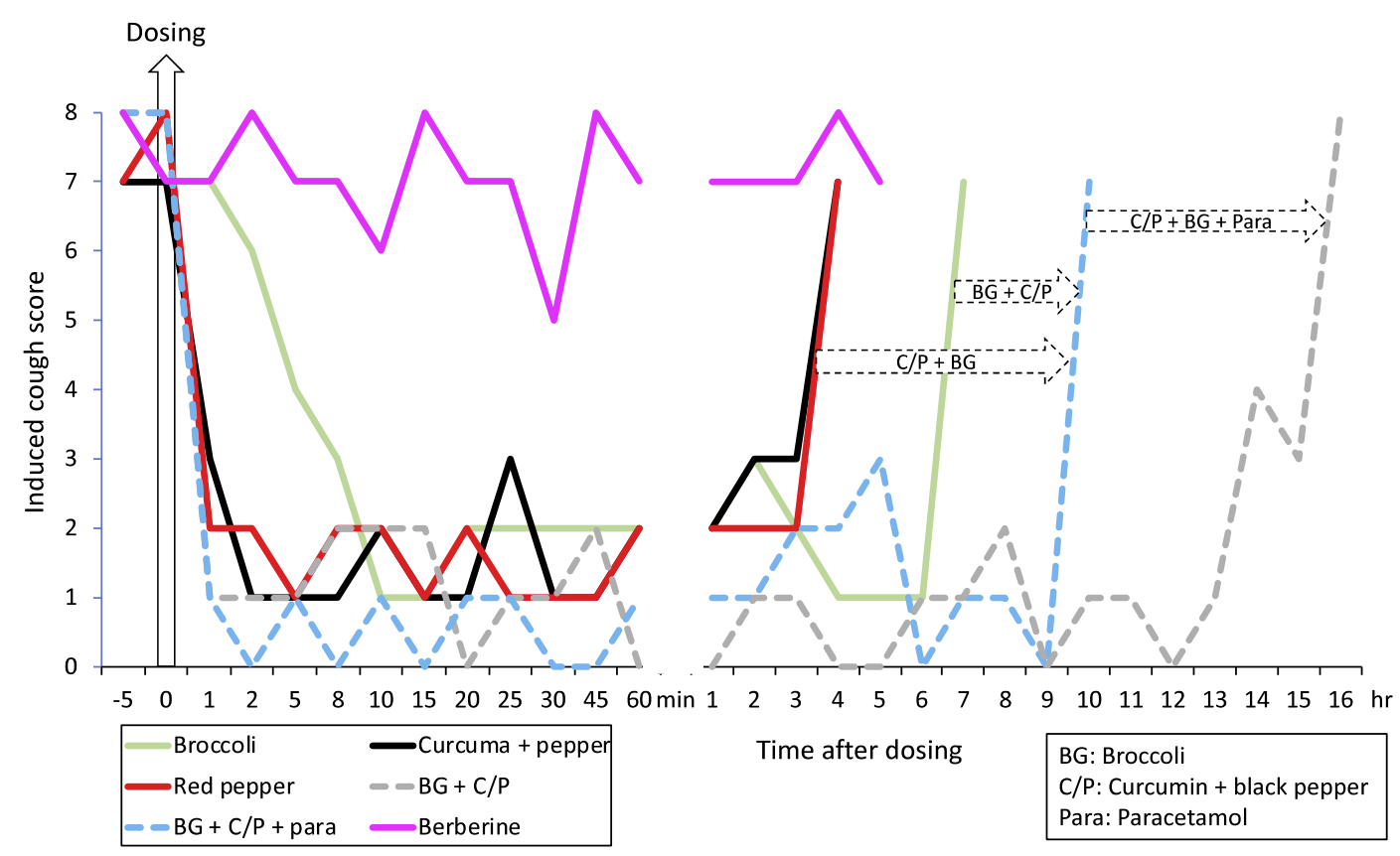

Fig. 2. Induced cough challenges with Nrf2, TRPA1 and/or TRPV1 agonists (from [194]). In the same patients, open-labelled induced cough challenges were carried out before dosing with an agonist before challenge (-5 min), and after $1,2,5,8,10,15,30,25,30,45$, and 60 minutes and every hour until the cough score was $\geq 7$. The cough challenge was validated in a double-blind, placebo-controlled study [193]. Berberine (Nrf2) was ineffective. Red pepper $20 \mathrm{mg}$ (Nrf2 low + TRPV1 high) or curcumin $100 \mathrm{mg}+$ black pepper $16 \mathrm{mg}$ (Nrf2 low + TRPA1 high + TRPV1 low) were effective within 1-2 minutes, and their effect persisted for up to 3 hours.

plasmic reticulum stress [192]. It has, however, never been proposed that TRPA1/TRPV1 may be involved in COVID-19 (Fig. 1).

Antioxidants inducing Nrf2 activation have been proposed to treat COVID-19 [10,18-20]. Antioxidants may be of interest, but their clinical benefits are unlikely to be seen in minutes, and the effect may not be optimal. In 3 clinical cases of proven COVID-19, capsules of broccoli seeds containing glucoraphanin and paracetamol were found to induce a rapid improvement (minutes) of some symptoms such as cough (submitted, published online [193]). Double-blind, placebo-controlled induced cough challenges in 1 patient showed a reduction of cough within 10 minutes.

Other hypotheses can also be proposed. TRPA1/ TRPV1 are involved in several common COVID-19 symptoms. TRPA1 more than TRPV1 can be activated by
Broccoli 300 mg (Nrf2 high + TRPA1 low) was effective within 10 minutes and its effect persisted for up to 6 hours. Broccoli $150 \mathrm{mg}$ + curcumin $50 \mathrm{mg}$ + black pepper $6 \mathrm{mg}$ were effective for up to 9 hours. Broccoli $150 \mathrm{mg}+$ curcumin $50 \mathrm{mg}+$ black pepper $6 \mathrm{mg}+$ paracetamol $250 \mathrm{mg}$ (paracetamol metabolites: TRPA1 + TRPV1) were effective for up to 16 hours. These results suggest a very fast TRPA1-TRPV1 desensitization and a cross talk with Nrf2 to increase the duration of the effect. TRPA1, transient receptor potential ankyrin 1; TRPV1, transient receptor potential vanilloid 1; Nrf2, nuclear factor (erythroid-derived 2).

ROS and may therefore be upregulated in COVID-19. Reducing ROS by Nrf2 will most likely reduce TRPA1 hyperreactivity, thereby reducing TRPA 1 activation by exogenous or endogenous agents. However, such a mechanism is likely to take time and cannot be involved in very rapid-onset clinical benefits. It may take an hour or more to find this synergy.

The activation of TRPA1/TRPV 1 by exogenous agents can lead to a rapid dose-dependent desensitization that may be effective within minutes and for up to a few hours, suggesting a symptomatic improvement. This rapid-onset mechanism may be sustained by antioxidants or other products. This proposal seems to be substantiated by preliminary clinical studies, but these observations need to be confirmed through formal studies. Double-blind, open labelled induced cough challenges in 1 patient showed a reduction of cough within 2 minutes with TRPA1/V1 ag- 
onists (green tea, curcumin, ginger, and red pepper) and suggested a synergy with Nrf2 (broccoli) for an increased duration of the effect (Fig. 2, submitted, available online [194]).

Another form of TRP desensitization is "tachyphylaxis," which is a reduction or the disappearance in the response to repeated applications of agonists [168, 195, 196]. In Asian or Sub-Saharan countries, large amounts of spices are regularly eaten and it is likely that TRPA1/ TRPV1 receptors are permanently desensitized or may have been reduced in numbers, allowing people to eat large amounts without side effects. In this model, Nrf2 and antioxidants may play an important additive role in reducing ROS. It is therefore possible that TRPA1/V1 tachyphylaxis may reduce the severity of COVID-19 symptoms, and even possibly reduce infection by SARSCoV-2. The long-term consumption of kimchi, which contains pungent nutrients and fermented cabbage, could be a prototype.

The results of these limited clinical studies cannot be taken as formal evidence. However, they have contributed to developing a proof-of-concept for the hypothesis that combined Nrf2-TRPA1 foods may be beneficial for some COVID-19 symptoms and that there is a synergy between Nrf2 and TRPA1 agonists. Before any conclusion can be drawn and these treatments recommended for COVID-19, the data warrant confirmation. In particular, the benefits of the foods need to be assessed in more severe and/or hospitalized patients, through large studies employing a double-blind, placebo-controlled design.
There are several unknown issues. The first is the interplay between TRPA1 and TRPV1 in desensitization. The second is the regulation of these channels by oxidative stress and the synergistic role of Nrf2. TRVP1 desensitization by capsaicin patches may be of benefit for COVID-19. It may also be of interest to combine Nrf2-potent agonists such as broccoli. However, again, these hypotheses cannot be used in practice before obtaining the results of mechanistic studies and formal clinical trials.

\section{Conflict of Interest Statement}

The authors have no conflicts of interest to declare.

\section{Funding Sources}

This article did not receive any funding.

\section{Author Contributions}

J.B. proposed the concept and discussed it with W.C., J.M.A., and T.Z. H.B., J.P.C., R.d.I.T., V.L.M., N.P.L., and A.B. were part of the think tank group. S.C.F. and G.I. discussed the food data. N.P.Z., V.L.M., I.A., C.A.A., G.W.C., A.A.C., A.F., J.F., S.F., B.G., T.H., J.C.I., M.J., L.K., P.K., D.L.L., A.M., E.M., Y.O., N.G.P., O.P., F.R., J.R., Y.R., P.P.R., B.S., A.S., S.T.S., A.V., H.J.C., and H.J.K. were requested to comment on the concept and to review the paper. All authors accepted the paper.

\section{References}

1 Fernandes ES, Fernandes MA, Keeble JE. The functions of TRPA1 and TRPV1: moving away from sensory nerves. Br J Pharmacol. 2012;166(2):510-21.

2 Jordt SE, Bautista DM, Chuang HH, McKemy DD, Zygmunt PM, Högestätt ED, et al. Mustard oils and cannabinoids excite sensory nerve fibres through the TRP channel ANKTM1. Nature. 2004;427(6971):260-5.

3 Talavera K, Startek JB, Alvarez-Collazo J, Boonen B, Alpizar YA, Sanchez A, et al. Mammalian transient receptor potential TRPA1 channels: from structure to disease. Physiol Rev. 2020;100(2):725-803.

4 Kadkova A, Synytsya V, Krusek J, Zimova L, Vlachova V. Molecular basis of TRPA1 regulation in nociceptive neurons. A review. Physiol Res. 2017;66(3):425-39.
5 Zheng W, Wen H. Heat activation mechanism of TRPV1: new insights from molecular dynamics simulation. Temperature. 2019; 6(2):120-31.

6 Zhao J, Lin King JV, Paulsen CE, Cheng Y, Julius D. Irritant-evoked activation and calcium modulation of the TRPA1 receptor. Nature. 2020;585(7823):141-5.

7 Bevan S, Quallo T, Andersson DA. Trpv1. Handb Exp Pharmacol. 2014;222:207-45.

8 Fonseca S, Rivas I, Romaguera D, Quijal M, Czarlewski W, Vidal A, et al. Association between consumption of fermented vegetables and COVID-19 mortality at a country level in Europe MEDRXIV/2020/147025. 2020.

9 Fonseca S, Rivas I, Romaguera D, Quijal M, Czarlewski W, Vidal A, et al. Association between consumption of vegetables and COVID-19 mortality at a country level in Europe. MedRix. 2020.
10 Bousquet J, Anto JM, Czarlewski W, Haahtela $\mathrm{T}$, Fonseca SC, Iaccarino G, et al. Cabbage and fermented vegetables: from death rate heterogeneity in countries to candidates for mitigation strategies of severe COVID-19. Allergy. 2020.

11 Elsayed Y, Khan NA. Immunity-boosting spices and the novel coronavirus. ACS Chem Neurosci. 2020;11(12):1696-8.

12 Mohammed A, Islam MS. Spice-derived bioactive ingredients: potential agents or food adjuvant in the management of diabetes mellitus. Front Pharmacol. 2018;9:893.

13 Tamang JP, Cotter PD, Endo A, Han NS, Kort R, Liu SQ, et al. Fermented foods in a global age: East meets West. Compr Rev Food Sci Food Saf. 2020;19(1):184-217. 
14 Suhail S, Zajac J, Fossum C, Lowater H, McCracken C, Severson N, et al. Role of oxidative stress on SARS-CoV (SARS) and SARSCoV-2 (COVID-19) infection: a review. Protein J. 2020 Dec;39(6):644-56.

15 Bousquet J, Czarlewski W, Blain H, Zuberbier T, Anto J. Rapid response: why Germany's case fatality rate seems so low: is nutrition another possibility. BMJ. 2020.https://www. bmj.com/content/369/bmj.m1395/rr-12.

16 Bousquet J, Anto JM, Anto JM, Iaccarino G, Czarlewski W, Haahtela T, et al. Is diet partly responsible for differences in COVID-19 death rates between and within countries? Clin Transl Allergy. 2020;10(1):16.

17 Vomund S, Schäfer A, Parnham MJ, Brüne B, von Knethen A. Nrf2, the master regulator of anti-oxidative responses. Int J Mol Sci. 2017; 18(12):2772.

18 Cuadrado A, Pajares M, Benito C, JimenezVillegas J, Escoll M, Fernandez-Gines R, et al. Can activation of NRF2 be a strategy against COVID-19? Trends Pharmacol Sci. 2020 Sep; 41(9):598-610.

19 Hassan SM, Jawad MJ, Ahjel SW, Singh RB, Singh J, Awad SM, et al. The Nrf2 activator (DMF) and Covid-19: is there a possible role? Med Arch. 2020;74(2):134-8.

20 McCord JM, Hybertson BM, Cota-Gomez A, Geraci KP, Gao B. Nrf2 activator PB125 as a potential therapeutic agent against $\mathrm{CO}$ VID-19. Antioxidants. 2020 Jun 12;9(6): 518.

21 Nilius B, Appendino G. Spices: the savory and beneficial science of pungency. Rev Physiol Biochem Pharmacol. 2013;164:1-76.

22 Silverman HA, Chen A, Kravatz NL, Chavan SS, Chang EH. Involvement of neural transient receptor potential channels in peripheral inflammation. Front Immunol. 2020;11: 590261.

23 Hu Y, Sun J, Dai Z, Deng H, Li X, Huang Q, et al. Prevalence and severity of corona virus disease 2019 (COVID-19): a systematic review and meta-analysis. J Clin Virol. 2020; 127:104371.

24 Millqvist E. TRPV1 and TRPM8 in treatment of chronic cough. Pharmaceuticals. 2016; 9(3):45.

25 Bonvini SJ, Belvisi MG. Cough and airway disease: the role of ion channels. Pulm Pharmacol Ther. 2017;47:21-8.

26 Taylor-Clark TE. Role of reactive oxygen species and TRP channels in the cough reflex. Cell Calcium. 2016;60(3):155-62.

27 Mukhopadhyay I, Kulkarni A, KhairatkarJoshi N. Blocking TRPA1 in respiratory disorders: does it hold a promise? Pharmaceuticals. 2016;9(4):70.

28 Lee LY. TRPA1 ion channels: a gateway to airway irritation and reflex responses induced by inhaled oxidants. J Physiol. 2010;588(Pt 5): $747-8$.

29 Kanezaki M, Ebihara S, Gui P, Ebihara T, Kohzuki M. Effect of cigarette smoking on cough reflex induced by TRPV1 and TRPA1 stimulations. Respir Med. 2012;106(3):406-12.
30 Wang M, Zhang Y, Xu M, Zhang H, Chen Y, Chung KF, et al. Roles of TRPA1 and TRPV1 in cigarette smoke -induced airway epithelial cell injury model. Free Radic Biol Med. 2019; 134:229-38.

31 Hajna Z, Csekő K, Kemény Á, Kereskai L, Kiss $\mathrm{T}$, Perkecz A, et al. Complex regulatory role of the TRPA1 receptor in acute and chronic airway inflammation mouse models. Int J Mol Sci. 2020;21(11):4109.

32 Lechien JR, Chiesa-Estomba CM, De Siati DR, Horoi M, Le Bon SD, Rodriguez A, et al. Olfactory and gustatory dysfunctions as a clinical presentation of mild-to-moderate forms of the coronavirus disease (COVID-19): a multicenter European study. Eur Arch Otorhinolaryngol. 2020;277(8):225161.

33 Izquierdo-Dominguez A, Rojas-Lechuga MJ, Mullol J, Alobid I. Olfactory dysfunction in the COVID-19 outbreak. J Investig Allergol Clin Immunol. 2020;30(5):317-26.

34 Nepal G, Rehrig JH, Shrestha GS, Shing YK, Yadav JK, Ojha R, et al. Neurological manifestations of COVID-19: a systematic review. Crit Care. 2020;24(1):421.

35 Salmon Ceron D, Bartier S, Hautefort C, Nguyen Y, Nevoux J, Hamel AL, et al. Selfreported loss of smell without nasal obstruction to identify COVID-19. The multicenter Coranosmia cohort study. J Infect. 2020; 81(4):614-20.

36 Izquierdo-Dominguez A, Rojas-Lechuga MJ, Chiesa-Estomba C, Calvo-Henriquez C, Ninchritz-Becerra E, Soriano-Reixach M, et al. Smell and taste dysfunction in COVID-19 is associated with younger age in ambulatory settings: a Multicenter Cross-Sectional Study. J Investig Allergol Clin Immunol. 2020;30(5): 346-57.

37 Mullol J, Alobid I, Mariño-Sánchez F, Izquierdo-Domínguez A, Marin C, Klimek L, et al. The loss of smell and taste in the COVID-19 outbreak: a tale of many countries. Curr Allergy Asthma Rep. 2020;20(10):61.

38 Poletti SC, Hausold J, Herrmann A, Witt M, Hummel T. Topographical distribution of trigeminal receptor expression in the nasal cavity. Rhinology. 2019;57(2):147-52.

39 Schutz M, Oertel BG, Heimann D, Doehring A, Walter C, Dimova V, et al. Consequences of a human TRPA1 genetic variant on the perception of nociceptive and olfactory stimuli. PLoS One. 2014;9(4):e95592.

40 Cecchini MP, Riello M, Sandri A, Zanini A, Fiorio M, Tinazzi M. Smell and taste dissociations in the modulation of tonic pain perception induced by a capsaicin cream application. Eur J Pain. 2020 Nov;24(10):1946-1955.

41 Frasnelli J, Albrecht J, Bryant B, Lundström JN. Perception of specific trigeminal chemosensory agonists. Neuroscience. 2011;189: 377-83.

42 Piochi M, Cabrino G, Morini G, Torri L. Individual differences in the perception of orthonasal irritation induced by food. Appetite. 2020;144:104460.
43 Simon SA, Gutierrez R. TRP channels at the periphery of the taste and trigeminal systems. In: Emir TLR, editor. Neurobiology of TRP channels. Frontiers in neuroscience. Boca Raton, FL; 2017. p. 113-24.

44 Nachtigal D, Andrew K, Green BG. Selective effects of temperature on the sensory irritation but not taste of nacl and citric acid. Chem Senses. 2019;44(1):61-8.

45 Green BG, Hayes JE. Capsaicin as a probe of the relationship between bitter taste and chemesthesis. Physiol Behav. 2003;79(4-5): 811-21.

46 Mao R, Qiu Y, He JS, Tan JY, Li XH, Liang J, et al. Manifestations and prognosis of gastrointestinal and liver involvement in patients with COVID-19: a systematic review and meta-analysis. Lancet Gastroenterol Hepatol. 2020;5(7):667-78.

47 Purhonen AK, Louhivuori LM, Kiehne K, Kerman KE, Herzig KH. TRPA1 channel activation induces cholecystokinin release via extracellular calcium. FEBS Lett. 2008;582(2): 229-32.

48 Nakajima S, Hira T, Yahagi A, Nishiyama C, Yamashita T, Imagi J, et al. Unsaturated aldehydes induce CCK secretion via TRPA1 in STC-1 cells. Mol Nutr Food Res. 2014;58(5): 1042-51.

49 Tominaga M, Momonaka Y, Yokose C, Tadaishi M, Shimizu M, Yamane T, et al. Anorexic action of deoxynivalenol in hypothalamus and intestine. Toxicon. 2016;118:54-60.

$50 \mathrm{Wu}$ W, Zhou HR, Pestka JJ. Potential roles for calcium-sensing receptor (CaSR) and transient receptor potential ankyrin-1 (TRPA1) in murine anorectic response to deoxynivalenol (vomitoxin). Arch Toxicol. 2017;91(1):495507.

51 Ohara K, Fukuda T, Ishida Y, Takahashi C, Ohya R, Katayama M, et al. $\beta$-Eudesmol, an oxygenized sesquiterpene, stimulates appetite via TRPA1 and the autonomic nervous system. Sci Rep. 2017;7(1):15785.

52 Christie S, Wittert GA, Li H, Page AJ. Involvement of TRPV1 channels in energy homeostasis. Front Endocrinol. 2018;9:420.

53 Speth MM, Singer-Cornelius T, Oberle M, Gengler I, Brockmeier SJ, Sedaghat AR. Olfactory dysfunction and sinonasal symptomatology in COVID-19: prevalence, severity, timing, and associated characteristics. Otolaryngol Head Neck Surg. 2020;163(1):114-20.

54 Parma V, Ohla K, Veldhuizen MG, Niv MY, Kelly CE, Bakke AJ, et al. More than smellCOVID-19 is associated with severe impairment of smell, taste, and chemesthesis. Chem Senses. 2020;45(7):609-22.

55 Alenmyr L, Högestätt ED, Zygmunt PM, Greiff L. TRPV1-mediated itch in seasonal allergic rhinitis. Allergy. 2009;64(5):807-10.

56 Kortekaas Krohn I, Callebaut I, Alpizar YA, Steelant B, Van Gerven L, Skov PS, et al. MP29-02 reduces nasal hyperreactivity and nasal mediators in patients with house dust mite-allergic rhinitis. Allergy. 2018;73(5): 1084-93. 
57 Van Gerven L, Alpizar YA, Steelant B, Callebaut I, Kortekaas Krohn I, Wouters M, et al. Enhanced chemosensory sensitivity in patients with idiopathic rhinitis and its reversal by nasal capsaicin treatment. J Allergy Clin Immunol. 2017;140(2):437-e2.

58 Van Gerven L, Steelant B, Alpizar YA, Talavera K, Hellings PW. Therapeutic effect of capsaicin nasal treatment in patients with mixed rhinitis unresponsive to intranasal steroids. Allergy. 2018;73(1):248-50.

59 Gevorgyan A, Segboer C, Gorissen R, van Drunen CM, Fokkens W. Capsaicin for nonallergic rhinitis. Cochrane Database Syst Rev. 2015;7(7):CD010591.

60 Fuhrer M, Dejaco C, Kopp B, Hammer J. Gastric administration of garlic powder containing the trpa1-agonist allicin induces specific epigastric symptoms and gastric relaxation in healthy subjects. Neurogastroenterol Motil. 2019;31(1):e13470.

61 Patcharatrakul T, Gonlachanvit S. Chili peppers, curcumins, and prebiotics in gastrointestinal health and disease. Curr Gastroenterol Rep. 2016;18(4):19.

62 Kindt S, Vos R, Blondeau K, Tack J. Influence of intra-oesophageal capsaicin instillation on heartburn induction and oesophageal sensitivity in man. Neurogastroenterol Motil. 2009;21(10):1032-e82.

63 Holzer P. Transient receptor potential (TRP) channels as drug targets for diseases of the digestive system. Pharmacol Ther. 2011;131(1): 142-70.

64 Abdullahi A, Candan SA, Abba MA, Bello AH, Alshehri MA, Afamefuna Victor E, et al. Neurological and musculoskeletal features of COVID-19: a systematic review and metaanalysis. Front Neurol. 2020;11:687.

65 Ro JY, Lee JS, Zhang Y. Activation of TRPV1 and TRPA1 leads to muscle nociception and mechanical hyperalgesia. Pain. 2009;144(3): 270-7.

66 Moore C, Gupta R, Jordt SE, Chen Y, Liedtke WB. Regulation of pain and itch by TRP channels. Neurosci Bull. 2018;34(1):120-42.

67 Marics B, Peitl B, Varga A, Pázmándi K, Bácsi A, Németh J, et al. Diet-induced obesity alters dural CGRP release and potentiates TRPA1-mediated trigeminovascular responses. Cephalalgia. 2017;37(6):581-91.

68 Kong X, Tu Y, Li B, Zhang L, Feng L, Wang L, et al. Roux-en- $Y$ gastric bypass enhances insulin secretion in type 2 diabetes via FXR-mediated TRPA1 expression. Mol Metab. 2019; 29:1-11.

69 Derbenev AV, Zsombok A. Potential therapeutic value of TRPV 1 and TRPA1 in diabetes mellitus and obesity. Semin Immunopathol. 2016;38(3):397-406.

70 Zhu R, Liu H, Liu C, Wang L, Ma R, Chen B, et al. Cinnamaldehyde in diabetes: a review of pharmacology, pharmacokinetics and safety. Pharmacol Res. 2017;122:78-89.
71 Wang J, Zhang X, Lan H, Wang W. Effect of garlic supplement in the management of type 2 diabetes mellitus (T2DM): a meta-analysis of randomized controlled trials. Food Nutr Res. 2017;61(1):1377571.

72 Camacho S, Michlig S, de Senarclens-Bezençon C, Meylan J, Meystre J, Pezzoli M, et al. Anti-obesity and anti-hyperglycemic effects of cinnamaldehyde via altered ghrelin secretion and functional impact on food intake and gastric emptying. Sci Rep. 2015;5:7919.

73 Nahama A, Ramachandran R, Cisternas AF, Ji H. The role of afferent pulmonary innervation in ARDS associated with COVID-19 and potential use of resiniferatoxin to improve prognosis: a review. Med Drug Discov. 2020; 5:100033.

74 Achanta S, Jordt SE. Transient receptor potential channels in pulmonary chemical injuries and as countermeasure targets. Ann N Y Acad Sci. 2020 Nov;1480(1):73-103.

75 Liu Z, Wang P, Lu S, Guo R, Gao W, Tong H, et al. Liquiritin, a novel inhibitor of TRPV1 and TRPA1, protects against LPS-induced acute lung injury. Cell Calcium. 2020;88: 102198.

76 Wang S, Shi P, Wang Y. TRPA1 ion channels in vagal afferent nerves contribute to ventilator-induced lung injury in a rat model. Gen Physiol Biophys. 2013;32(3):389-94.

77 Conklin DJ, Haberzettl P, Jagatheesan G, Kong M, Hoyle GW. Role of TRPA1 in acute cardiopulmonary toxicity of inhaled acrolein. Toxicol Appl Pharmacol. 2017;324:61-72.

78 Lee LY, Hsu CC, Lin YJ, Lin RL, Khosravi M. Interaction between TRPA 1 and TRPV1: synergy on pulmonary sensory nerves. Pulm Pharmacol Ther. 2015;35:87-93.

79 Wang Z, Ye D, Ye J, Wang M, Liu J, Jiang H, et al. The TRPA1 channel in the cardiovascular system: promising features and challenges. Front Pharmacol. 2019;10:1253.

80 Frijhoff J, Winyard PG, Zarkovic N, Davies SS, Stocker R, Cheng D, et al. Clinical relevance of biomarkers of oxidative stress. Antioxid Redox Signal. 2015;23(14):1144-70.

81 Halliwell B. Antioxidants in human health and disease. Annu Rev Nutr. 1996;16:33-50.

82 Andersson DA, Gentry C, Moss S, Bevan S. Transient receptor potential A1 is a sensory receptor for multiple products of oxidative stress. J Neurosci. 2008;28(10):2485-94.

83 Shimizu S, Takahashi N, Mori Y. TRPs as chemosensors (ROS, RNS, RCS, gasotransmitters). Handb Exp Pharmacol. 2014;223:767-94.

84 Viana F. TRPA1 channels: molecular sentinels of cellular stress and tissue damage. J Physiol. 2016;594(15):4151-69.

85 Toth A, Czikora A, Pasztor ET, Dienes B, Bai $\mathrm{P}$, Csernoch L, et al. Vanilloid receptor-1 (TRPV1) expression and function in the vasculature of the rat. J Histochem Cytochem. 2014;62(2):129-44.

86 Ma L, Zhong J, Zhao Z, Luo Z, Ma S, Sun J, et al. Activation of TRPV1 reduces vascular lipid accumulation and attenuates atherosclerosis. Cardiovasc Res. 2011;92(3):504-13.
87 Poonyachoti S, Kulkarni-Narla A, Brown DR. Chemical coding of neurons expressing deltaand kappa-opioid receptor and type I vanilloid receptor immunoreactivities in the porcine ileum. Cell Tissue Res. 2002;307(1):2333.

88 Szabados T, Gomori K, Palvolgyi L, Gorbe A, Baczko I, Helyes Z, et al. Capsaicin-sensitive sensory nerves and the TRPV1 ion channel in cardiac physiology and pathologies. Int $\mathrm{J} \mathrm{Mol}$ Sci. 2020;21(12).

89 Wang D, Wu Y, Chen Y, Wang A, Lv K, Kong $\mathrm{X}$, et al. Focal selective chemo-ablation of spinal cardiac afferent nerve by resiniferatoxin protects the heart from pressure overload-induced hypertrophy. Biomed Pharmacother. 2019;109:377-85

90 Taylor-Clark TE, Undem BJ. Sensing pulmonary oxidative stress by lung vagal afferents. Respir Physiol Neurobiol. 2011;178(3):40613.

91 Silva-Islas CA, Maldonado PD. Canonical and non-canonical mechanisms of Nrf2 activation. Pharmacol Res. 2018;134:92-9.

$92 \mathrm{Gu}$ X, Yu N, Pang X, Zhang W, Zhang J, Zhang Y. EXPRESS: products of oxidative stress and TRPA1 expression in the brainstem of rats after lung ischemia-reperfusion injury. Pulm Circ. 2019;9(3):2045894019865169.

93 Kimura H. Hydrogen polysulfide ( $\mathrm{H} 2 \mathrm{~S} \mathrm{n}$ ) signaling along with hydrogen sulfide (H2S) and nitric oxide (NO). J Neural Transm. 2016; 123(11):1235-45.

94 Ma S, Wang DH. Knockout of Trpal exacerbates renal ischemia-reperfusion injury with classical activation of macrophages. Am J Hypertens. 2020.

95 Xiong W, MacColl Garfinkel AE, Li Y, Benowitz LI, Cepko CL. NRF2 promotes neuronal survival in neurodegeneration and acute nerve damage. J Clin Invest. 2015;125(4): 1433-45.

96 Wang GQ, Zhang B, He XM, Li DD, Shi JS, Zhang F. Naringenin targets on astroglial Nrf2 to support dopaminergic neurons. Pharmacol Res. 2019;139:452-9.

97 Zhu L, Li D, Chen C, Wang G, Shi J, Zhang F. Activation of Nrf2 signaling by Icariin protects against 6-OHDA-induced neurotoxicity. Biotechnol Appl Biochem. 2019;66(3): 465-71.

98 Liu YW, Liu XL, Kong L, Zhang MY, Chen YJ, Zhu X, et al. Neuroprotection of quercetin on central neurons against chronic high glucose through enhancement of Nrf2/ARE/glyoxalase-1 pathway mediated by phosphorylation regulation. Biomed Pharmacother. 2019;109: 2145-54

99 Takahashi N, Chen HY, Harris IS, Stover DG, Selfors LM, Bronson RT, et al. Cancer Cells Co-opt the neuronal redox-sensing channel TRPA1 to promote oxidative-stress tolerance. Cancer Cell. 2018;33(6):985-e7. 
100 Joung EJ, Li MH, Lee HG, Somparn N, Jung $\mathrm{YS}, \mathrm{Na} \mathrm{HK}$, et al. Capsaicin induces heme oxygenase- 1 expression in HepG2 cells via activation of $\mathrm{PI} 3 \mathrm{~K}-\mathrm{Nrf} 2$ signaling: $\mathrm{NAD}(\mathrm{P})$ $\mathrm{H}$ :quinone oxidoreductase as a potential target. Antioxid Redox Signal. 2007;9(12): 2087-98.

101 McCarty MF, DiNicolantonio JJ, O'Keefe JH. Capsaicin may have important potential for promoting vascular and metabolic health. Open Heart. 2015;2(1):e000262.

102 Huang KF, Ma KH, Jhap TY, Liu PS, Chueh $\mathrm{SH}$. Ultraviolet B irradiation induced Nrf2 degradation occurs via activation of TRPV1 channels in human dermal fibroblasts. Free Radic Biol Med. 2019;141:220-32.

$103 \mathrm{Xu}$ J, Lazartigues E. Expression of ACE2 in human neurons supports the neuro-invasive potential of COVID-19 virus. Cell Mol Neurobiol. 2020 Jul 4:1-5.

104 Brann DH, Tsukahara T, Weinreb C, Lipovsek M, Van den Berge K, Gong B, et al. Non-neuronal expression of SARS-CoV-2 entry genes in the olfactory system suggests mechanisms underlying COVID-19-associated anosmia. Sci Adv. 2020;6(31):eabc5801.

105 Cooper KW, Brann DH, Farruggia MC, Bhutani S, Pellegrino R, Tsukahara T, et al. COVID-19 and the chemical senses: supporting players take center stage. Neuron. 2020;107(2):219-33.

106 Bullen CK, Hogberg HT, Bahadirli-Talbott A, Bishai WR, Hartung T, Keuthan C, et al. Infectability of human BrainSphere neurons suggests neurotropism of SARS-CoV-2. ALTEX. 2020;37(4):665-671.

107 Bilinska K, Jakubowska P, Von Bartheld CS, Butowt R. Expression of the SARS-CoV-2 entry proteins, ACE2 and TMPRSS2, in cells of the olfactory epithelium: identification of cell types and trends with age. ACS Chem Neurosci. 2020;11(11):1555-62.

108 Azizi SA, Azizi SA. Neurological injuries in COVID-19 patients: direct viral invasion or a bystander injury after infection of epithelial/endothelial cells. J Neurovirol. 2020; 26(5):631-41.

109 Samanta A, Hughes TET, Moiseenkova-Bell VY. Transient receptor potential (TRP) channels. Subcell Biochem. 2018;87:141-65.

110 Bousquet J, Cristol J, Czarlewski W, Anto J, Martineau A, Haahtela T, et al. Nrf2-interacting nutrients and COVID-19: time for research to develop adaptation strategies. Clin Transl Allergy. 2020 Dec 3;10(1):58.

111 Macpherson LJ, Geierstanger BH, Viswanath V, Bandell M, Eid SR, Hwang S, et al. The pungency of garlic: activation of TRPA1 and TRPV1 in response to allicin. Curr Biol. 2005;15(10):929-34.

112 Kurogi M, Kawai Y, Nagatomo K, Tateyama M, Kubo Y, Saitoh O. Auto-oxidation products of epigallocatechin gallate activate TRPA1 and TRPV1 in sensory neurons. Chem Senses. 2015;40(1):27-46.
113 Peixoto-Neves D, Soni H, Adebiyi A. CGRPergic nerve TRPA1 channels contribute to epigallocatechin gallate-induced neurogenic vasodilation. ACS Chem Neurosci. 2019;10(1):216-20.

114 Borgonovo G, Zimbaldi N, Guarise M, De Nisi P, De Petrocellis L, Schiano Moriello A, et al. Isothiocyanates and glucosinolates from sisymbrium officinale (L.) Scop. ("the Singers' Plant"): isolation and in vitro assays on the somatosensory and pain receptor TRPA1 channel. Molecules. 2019;24(5):949.

115 Borgonovo G, De Petrocellis L, Schiano Moriello A, Bertoli S, Leone A, Battezzati A, et al. Moringin, a stable isothiocyanate from moringa oleifera, activates the somatosensory and pain receptor TRPA1 channel in vitro. Molecules. 2020;25(4):976.

116 Nalli M, Ortar G, Moriello AS, Morera E, Di Marzo V, De Petrocellis L. TRPA1 channels as targets for resveratrol and related stilbenoids. Bioorg Med Chem Lett. 2016;26(3): 899-902.

117 Yu L, Wang S, Kogure Y, Yamamoto S, Noguchi K, Dai Y. Modulation of TRP channels by resveratrol and other stilbenoids. Mol Pain. 2013;9:3.

118 Takeda M, Takehana S, Sekiguchi K, Kubota Y, Shimazu Y. Modulatory mechanism of nociceptive neuronal activity by dietary constituent resveratrol. Int J Mol Sci. 2016; 17(10): 1702

119 Takehana S, Kubota Y, Uotsu N, Yui K, Iwata K, Shimazu Y, et al. The dietary constituent resveratrol suppresses nociceptive neurotransmission via the NMDA receptor. Mol Pain. 2017;13:1744806917697010.

120 Asgar J, Zhang Y, Saloman JL, Wang S, Chung MK, Ro JY. The role of TRPA1 in muscle pain and mechanical hypersensitivity under inflammatory conditions in rats. Neuroscience. 2015;310:206-15.

121 Everaerts W, Gees M, Alpizar YA, Farre R, Leten C, Apetrei A, et al. The capsaicin receptor TRPV1 is a crucial mediator of the noxious effects of mustard oil. Curr Biol. 2011;21(4):316-21.

122 Szallasi A, Szabó T, Bíró T, Modarres S, Blumberg PM, Krause JE, et al. Resiniferatoxin-type phorboid vanilloids display capsaicin-like selectivity at native vanilloid receptors on rat DRG neurons and at the cloned vanilloid receptor VR1. Br J Pharmacol. 1999;128(2):428-34.

123 Ogawa N, Kurokawa T, Mori Y. Sensing of redox status by TRP channels. Cell Calcium. 2016;60(2):115-22.

124 Ashrafizadeh M, Fekri HS, Ahmadi Z, Farkhondeh T, Samarghandian S. Therapeutic and biological activities of berberine: the involvement of Nrf2 signaling pathway. J Cell Biochem. 2020;121(2):1575-85.

125 Zan Y, Kuai CX, Qiu ZX, Huang F. Berberine ameliorates diabetic neuropathy: TRPV1 modulation by PKC pathway. Am J Chin Med. 2017;45(8):1-15.
126 Srinivasan K. Biological activities of red pepper (Capsicum annuum) and its pungent principle capsaicin: a review. Crit Rev Food Sci Nutr. 2016;56(9):1488-500.

127 Moran MM, Szallasi A. Targeting nociceptive transient receptor potential channels to treat chronic pain: current state of the field. Br J Pharmacol. 2018;175(12):2185-203.

128 Yang F, Zheng J. Understand spiciness: mechanism of TRPV1 channel activation by capsaicin. Protein Cell. 2017;8(3):169-77.

129 Furue M, Fuyuno Y, Mitoma C, Uchi H, Tsuji G. Therapeutic agents with AHR inhibiting and NRF2 activating activity for managing chloracne. Antioxidants. 2018; 7(7):90.

130 Watanabe T, Terada Y. Food compounds activating thermosensitive TRP channels in Asian herbal and medicinal foods. J Nutr Sci Vitaminol. 2015;61(Suppl):S86-8.

131 Malavolta M, Bracci M, Santarelli L, Sayeed MA, Pierpaoli E, Giacconi R, et al. Inducers of senescence, toxic compounds, and senolytics: the multiple faces of Nrf2-activating phytochemicals in cancer adjuvant therapy. Mediators Inflamm. 2018;2018:4159013.

132 Patel SS, Acharya A, Ray RS, Agrawal R, Raghuwanshi R, Jain P. Cellular and molecular mechanisms of curcumin in prevention and treatment of disease. Crit Rev Food Sci Nutr. 2020;60(6):887-939.

133 Nalli M, Ortar G, Schiano Moriello A, Di Marzo V, De Petrocellis L. Effects of curcumin and curcumin analogues on TRP channels. Fitoterapia. 2017;122:126-31.

134 Guo R, Zhou FM, Su CJ, Liu TT, Zhou Y, Fan $\mathrm{L}$, et al. Epigallocatechin-3-gallate attenuates acute and chronic psoriatic itch in mice: Involvement of antioxidant, anti-inflammatory effects and suppression of ERK and Akt signaling pathways. Biochem Biophys Res Commun. 2018;496(4):1062-8.

135 Yeh CM, Lin YJ, Hsu TH, Ruan T. Genistein suppressing the ROS-Induced hypersensitivity of rat vagal lung C-fiber afferents through an era-mediated mechanism. Chin J Physiol. 2018;61(1):14-24.

136 Kikuno S, Taguchi K, Iwamoto N, Yamano S, Cho AK, Froines JR, et al. 1,2-Naphthoquinone activates vanilloid receptor 1 through increased protein tyrosine phosphorylation, leading to contraction of guinea pig trachea. Toxicol Appl Pharmacol. 2006;210(1-2):47-54.

137 de Lima RMT, Dos Reis AC, de Menezes APM, Santos JVO, Filho JWGO, Ferreira JRO, et al. Protective and therapeutic potential of ginger (Zingiber officinale) extract and [6]-gingerol in cancer: a comprehensive review. Phytother Res. 2018;32(10):1885907.

138 Yang MQ, Ye LL, Liu XL, Qi XM, Lv JD, Wang $G$, et al. Gingerol activates noxious cold ion channel TRPA1 in gastrointestinal tract. Chin J Nat Med. 2016;14(6):434-40. 
139 Yin Y, Dong Y, Vu S, Yang F, Yarov-Yarovoy V, Tian Y, et al. Structural mechanisms underlying activation of TRPV1 channels by pungent compounds in gingers. Br J Pharmacol. 2019;176(17):3364-77.

140 Kong Y, Olejar KJ, On SLW, Chelikani V. The potential of lactobacillus spp. for modulating oxidative stress in the gastrointestinal tract. Antioxidants. 2020;9(7):610.

141 Yi R, Peng P, Zhang J, Du M, Lan L, Qian Y, et al. Lactobacillus plantarum CQPC02-fermented soybean milk improves loperamideinduced constipation in mice. J Med Food. 2019;22(12):1208-21.

142 Guimaraes MZP, Jordt SE. TRPA1: a sensory channel of many talents. In: Liedtke WB, Heller S, editors. TRP ion channel function in sensory transduction and cellular signaling cascades. Frontiers in Neuroscience. Boca Raton, FL; 2007.

143 Elbini Dhouib I, Jallouli M, Annabi A, Gharbi N, Elfazaa S, Lasram MM. A minireview on $\mathrm{N}$-acetylcysteine: an old drug with new approaches. Life Sci. 2016;151:359-63.

144 Stenger B, Popp T, John H, Siegert M, Tsoutsoulopoulos A, Schmidt A, et al. N-AcetylL-cysteine inhibits sulfur mustard-induced and TRPA1-dependent calcium influx. Arch Toxicol. 2017;91(5):2179-89.

145 Kose SA, Naziroglu M. N-acetyl cysteine reduces oxidative toxicity, apoptosis, and calcium entry through TRPV1 channels in the neutrophils of patients with polycystic ovary syndrome. Free Radic Res. 2015;49(3):33846.

146 Kaminskyy VO, Zhivotovsky B. Free radicals in cross talk between autophagy and apoptosis. Antioxid Redox Signal. 2014; 21(1):86-102.

147 Sakaguchi R, Mori Y. Transient receptor potential (TRP) channels: biosensors for redox environmental stimuli and cellular status. Free Radic Biol Med. 2020;146:36-44.

148 Wang-Sheng C, Jie A, Jian-Jun L, Lan H, Zeng-Bao X, Chang-Qing L. Piperine attenuates lipopolysaccharide (LPS)-induced inflammatory responses in BV2 microglia. Int Immunopharmacol. 2017;42:44-8.

149 Okumura Y, Narukawa M, Iwasaki Y, Ishikawa A, Matsuda $\mathrm{H}$, Yoshikawa $\mathrm{M}$, et al. Activation of TRPV1 and TRPA1 by black pepper components. Biosci Biotechnol Biochem. 2010;74(5):1068-72.

150 Dong Y, Yin Y, Vu S, Yang F, Yarov-Yarovoy $\mathrm{V}$, Tian $\mathrm{Y}$, et al. A distinct structural mechanism underlies TRPV1 activation by piperine. Biochem Biophys Res Commun. 2019;516(2):365-72.

151 Nakamura T, Miyoshi N, Ishii T, Nishikawa M, Ikushiro S, Watanabe T. Activation of transient receptor potential ankyrin 1 by quercetin and its analogs. Biosci Biotechnol Biochem. 2016;80(5):949-54
152 Li Z, Zhang J, Ren X, Liu Q, Yang X. The mechanism of quercetin in regulating osteoclast activation and the PAR2/TRPV1 signaling pathway in the treatment of bone cancer pain. Int J Clin Exp Pathol. 2018;11(11): 5149-56.

153 Nakao S, Mabuchi M, Wang S, Kogure Y, Shimizu T, Noguchi K, et al. Synthesis of resveratrol derivatives as new analgesic drugs through desensitization of the TRPA1 receptor. Bioorg Med Chem Lett. 2017;27(14): 3167-72.

154 Schwarz M, Lossow K, Kopp JF, Schwerdtle T, Kipp AP. Crosstalk of Nrf2 with the trace elements selenium, iron, zinc, and copper. Nutrients. 2019;11(9):2112.

155 Ozkal B, Ovey IS. Selenium enhances TRPA1 channel-mediated activity of temozolomide in SH-SY5Y neuroblastoma cells. Childs Nerv Syst. 2020;36(6):1283-92.

156 Kahya MC, Naziroglu M, Ovey IS. Modulation of diabetes-induced oxidative stress, apoptosis, and $\mathrm{Ca}(2+)$ entry through TRPM2 and TRPV1 channels in dorsal root ganglion and hippocampus of diabetic rats by melatonin and selenium. Mol Neurobiol. 2017;54(3):2345-60.

157 Hegazy AM, El-Sayed EM, Ibrahim KS, Abdel-Azeem AS. Dietary antioxidant for disease prevention corroborated by the $\mathrm{Nrf} 2$ pathway. J Complement Integr Med. 2019; 16(3).

158 Kim KS, Yoo HY, Park KS, Kim JK, Zhang YH, Kim SJ. Differential effects of acute hypoxia on the activation of TRPV1 by capsaicin and acidic pH. J Physiol Sci. 2012;62(2): 93-103.

159 Berridge MJ. Vitamin D, reactive oxygen species and calcium signalling in ageing and disease. Philos Trans R Soc Lond B Biol Sci. 2016;371(1700):20150434.

160 Tripathy B, Majhi RK. TRPV1 channel as the membrane vitamin $D$ receptor: solving part of the puzzle. J Physiol. 2020 Dec;598(24): 5601-3.

161 Korenori Y, Tanigawa S, Kumamoto T, Qin S, Daikoku Y, Miyamori K, et al. Modulation of Nrf2/Keap1 system by Wasabi 6-methylthiohexyl isothiocyanate in ARE-mediated NQO1 expression. Mol Nutr Food Res. 2013;57(5):854-64.

162 Terada Y, Masuda H, Watanabe T. Structure-activity relationship study on isothiocyanates: comparison of TRPA1-activating ability between allyl isothiocyanate and specific flavor components of Wasabi, Horseradish, and white mustard. J Nat Prod. 2015; 78(8):1937-41.

163 Steinritz D, Zehfuss F, Stenger B, Schmidt A, Popp T, Kehe K, et al. Zinc chloride-induced TRPA1 activation does not contribute to toxicity in vitro. Toxicol Lett. 2018;293:1339.

164 Luo J, Bavencoffe A, Yang P, Feng J, Yin S, Qian A, et al. Zinc inhibits TRPV1 to alleviate chemotherapy-induced neuropathic pain. J Neurosci. 2018;38(2):474-83.
165 Porszasg N, Jancso N. Studies on the action potentials of sensory nerves in animals desensitized with capsaicine. Acta Physiol Acad Sci Hung. 1959;16:299-306.

166 Rohacs T. Phosphoinositide regulation of TRPV1 revisited. Pflugers Arch. 2015; 467(9):1851-69.

167 Chen MZ, Zhu X, Sun HQ, Mao YS, Wei Y, Yamamoto $M$, et al. Oxidative stress decreases phosphatidylinositol 4,5-bisphosphate levels by deactivating phosphatidylinositol- 4-phosphate 5-kinase beta in a Syk-dependent manner. J Biol Chem. 2009; 284(35):23743-53.

168 Touska F, Marsakova L, Teisinger J, Vlachova V. A "cute" desensitization of TRPV1. Curr Pharm Biotechnol. 2011;12(1):122-9.

169 Akopian AN, Ruparel NB, Jeske NA, Hargreaves KM. Transient receptor potential TRPA1 channel desensitization in sensory neurons is agonist dependent and regulated by TRPV1-directed internalization. J Physiol. 2007;583(Pt 1):175-93.

170 Ruparel NB, Patwardhan AM, Akopian AN Hargreaves KM. Desensitization of transient receptor potential ankyrin 1 (TRPA1) by the TRP vanilloid 1-selective cannabinoid arachidonoyl-2 chloroethanolamine. $\mathrm{Mol}$ Pharmacol. 2011;80(1):117-23.

171 Nassini R, Materazzi S, Vriens J, Prenen J, Benemei S, De Siena G, et al. The "headache tree" via umbellulone and TRPA1 activates the trigeminovascular system. Brain. 2012; 135(Pt 2):376-90.

172 Ibarra Y, Blair NT. Benzoquinone reveals a cysteine-dependent desensitization mechanism of TRPA1. Mol Pharmacol. 2013;83(5): 1120-32.

173 Penuelas A, Tashima K, Tsuchiya S, Matsumoto K, Nakamura T, Horie S, et al. Contractile effect of TRPA1 receptor agonists in the isolated mouse intestine. Eur J Pharmacol. 2007;576(1-3):143-50

174 Beckel JM, de Groat WC. The effect of the electrophilic fatty acid nitro-oleic acid on TRP channel function in sensory neurons. Nitric Oxide. 2018.

175 Nie H, Xue X, Liu G, Guan G, Liu H, Sun L, et al. Nitro-oleic acid ameliorates oxygen and glucose deprivation/re-oxygenation triggered oxidative stress in renal tubular cells via activation of $\mathrm{Nrf} 2$ and suppression of NADPH oxidase. Free Radic Res. 2016; 50(11):1200-13.

176 Patil MJ, Salas M, Bialuhin S, Boyd JT, Jeske NA, Akopian AN. Sensitization of small-diameter sensory neurons is controlled by TRPV1 and TRPA1 association. FASEB J. 2020;34(1):287-302.

177 Dragan AV, Petrushenko OA, Burlak OP, Lukyanetz EA. Effect of Trpa1 receptor activation on Trpv1 channel desensitization in rat dorsal ganglion neurons. Fiziol Zh. 2016; 62(1):16-24. 
178 Kistner K, Siklosi N, Babes A, Khalil M, Selescu T, Zimmermann K, et al. Systemic desensitization through TRPA1 channels by capsazepine and mustard oil: a novel strategy against inflammation and pain. Sci Rep. 2016;6:28621.

179 Talavera K, Gees M, Karashima Y, Meseguer VM, Vanoirbeek JA, Damann N, et al. Nicotine activates the chemosensory cation channel TRPA1. Nat Neurosci. 2009;12(10): 1293-9.

180 Kichko TI, Lennerz J, Eberhardt M, Babes RM, Neuhuber W, Kobal G, et al. Bimodal concentration-response of nicotine involves the nicotinic acetylcholine receptor, transient receptor potential vanilloid type 1 , and transient receptor potential ankyrin 1 channels in mouse trachea and sensory neurons. J Pharmacol Exp Ther. 2013;347(2):529-39.

181 Farsalinos K, Angelopoulou A, Alexandris N, Poulas K. COVID-19 and the nicotinic cholinergic system. Eur Respir J. 2020;56(1): 2001589.

182 Mirrasekhian E, Nilsson JLÅ, Shionoya K, Blomgren A, Zygmunt PM, Engblom D, et al. The antipyretic effect of paracetamol occurs independent of transient receptor potential ankyrin 1-mediated hypothermia and is associated with prostaglandin inhibition in the brain. FASEB J. 2018;32(10):5751-9.

183 Fresno N, Pérez-Fernández R, Goicoechea C, Alkorta I, Fernández-Carvajal A, de la Torre-Martínez R, et al. Adamantyl analogues of paracetamol as potent analgesic drugs via inhibition of TRPA1. PLoS One. 2014;9(12):e113841.
184 Eberhardt MJ, Schillers F, Eberhardt EM, Risser L, de la Roche J, Herzog C, et al. Reactive metabolites of acetaminophen activate and sensitize the capsaicin receptor TRPV1. Sci Rep. 2017;7(1):12775.

185 Wang Y, Lin W, Wu N, He X, Wang J, Feng $\mathrm{Z}$, et al. An insight into paracetamol and its metabolites using molecular docking and molecular dynamics simulation. J Mol Model. 2018;24(9):243.

186 Copple IM, Goldring CE, Jenkins RE, Chia AJ, Randle LE, Hayes JD, et al. The hepatotoxic metabolite of acetaminophen directly activates the Keap1-Nrf2 cell defense system. Hepatology. 2008;48(4):1292-301.

187 Wojdyla K, Wrzesinski K, Williamson J, Fey SJ, Rogowska-Wrzesinska A. Acetaminophen-induced S-nitrosylation and S-sulfenylation signalling in 3D cultured hepatocarcinoma cell spheroids. Toxicol Res. 2016; 5(3):905-20.

188 Gum SI, Cho MK. Recent updates on acetaminophen hepatotoxicity: the role of nrf2 in hepatoprotection. Toxicol Res. 2013; 29(3):165-72.

189 Lv H, Hong L, Tian Y, Yin C, Zhu C, Feng $\mathrm{H}$. Corilagin alleviates acetaminophen-induced hepatotoxicity via enhancing the AMPK/GSK3 $\beta-N r f 2$ signaling pathway. Cell Commun Signal. 2019;17(1):2.

190 Ciccotti M, Raguzzini A, Sciarra T, Catasta G, Aiello P, Buccolieri C, et al. Nutraceutical-based integrative medicine: adopting a mediterranean diet pyramid for attaining healthy ageing in veterans with disabilities. Curr Pharm Des. 2018;24(35):4186-96.
191 Silvagno F, Vernone A, Pescarmona GP. The role of glutathione in protecting against the severe inflammatory response triggered by COVID-19. Antioxidants. 2020;9(7):624.

192 Banerjee A, Czinn SJ, Reiter RJ, Blanchard TG. Crosstalk between endoplasmic reticulum stress and anti-viral activities: a novel therapeutic target for COVID-19. Life Sci. 2020;255:117842.

193 Bousquet J, Le-Moing V, Blain H, Czarlewski $\mathrm{W}$, Zuberbier T, de-la-Torre R, et al. Efficacy of broccoli and glucoraphanin in COVID-19: From hypothesis to proof- of-concept with three experimental clinical cases. World Allergy Organ J. 2020 Dec 9;14(1):100498.http: //wwwga2lennet/PDF/06Clinical\%20casesbroccolipdf http: //dx.doi.org/10.22541/ au.159493397.79345039.

194 Bousquet J, Czarlewski W, Zuberbier T, dela-Torre R, Anto J. Induced cough challenges in a single patient with COVID-19 showing an interplay between Nrf2, TRPA1 and TRPV1 agonists. 2020.

195 Tian Q, Hu J, Xie C, Mei K, Pham C, Mo X, et al. Recovery from tachyphylaxis of TRPV1 coincides with recycling to the surface membrane. Proc Natl Acad Sci U S A. 2019; 116(11):5170-5.

196 Sanz-Salvador L, Andrés-Borderia A, Ferrer-Montiel A, Planells-Cases R. Agonistand $\mathrm{Ca} 2+-$ dependent desensitization of TRPV1 channel targets the receptor to lysosomes for degradation. J Biol Chem. 2012; 287(23):19462-71. 